\title{
Assessment of Treadmill Exercise Test Preparation in Mosul Cardiac Center
}

\author{
Zahraa H. Ismaeel AL-Ridhwany* \\ Zaid Abedel-Elah Mustafa Al- Najjar** \\ Salah Mahdy Majeed***
}

\author{
FICMS(F.M) \\ FICMS(med.) \\ FICMS(med.),CABMS(med.),FICMS(cardio.)
}

\begin{abstract}
:
Fac Med Baghdad

2016; Vol.58, No.3

Received:May, 2016

Accepted: July.2016

Background: The exercise ECG has a role in articulating the clinical history through stimulating symptoms such as chest pain (which is the most common presenting complaint indicating coronary artery disease and is seen frequently by primary care physicians) and breathlessness, and prompting additional details about their symptoms so it can facilitate communication between patient and clinician as the evaluation of chest pain can be very difficult since it is possible to have a normal resting ECG with considerable narrowing of the coronary arteries.

Objectives: This study sought to assess the roles of preparation for treadmill and the frequency of inconclusive result.

Methods: The study sample consisted of persons of all ages and both sexes attending the exercise units during the study period in Mosul city, Iraq were included in the research and the collection of cases started from the 1st of January 2012 to 1 st of June 2012.

Results: The present study included a sample of 593 patients during the study period. The mean age of patients was $49 \pm 9$ years. Mean age of males patients ( $48.7 \pm 9$ years) compared with the females' mean age $(50.3 \pm 8$ years $)(\mathrm{p}=0.000)$. The percentage of unprepared group for testing in the present study sample were $23.1 \%$, a condition that was significantly associated with inconclusive result in general $(\mathrm{p}=0.000)$ and incomplete result in specific $(\mathrm{p}=0.001)$. On the other hand, $67.9 \%$ of patients were well prepared.

Conclusion: It was concluded that patients must be well prepared for exercise tolerance test. They should not only know the purpose of the test, but also signs and symptoms that indicate the test should be stopped.

Keywords: Treadmill exercise, Patient preparation, Accuracy of result.
\end{abstract}

\section{Introduction:}

Heart disease is the second leading condition among patient attending the family physicians clinic $(1,2)$. The exercise electrocardiography (ECG) is usually the first initial noninvasive stress test, easy to perform, widely available and safe measure for patients with known or suspected cardiovascular disease (CVD) who are able to exercise and have a normal baseline ECG $(3,4,5,6)$.Cardiovascular exercise stress testing was first noticed by Feil and Seigel in 1928; they reported S-T and $\mathrm{T}$ changes following exercise, it was introduce next to a standardized exercise protocol to assess functional capacity and hemodynamic response $(7,8,9,10,11)$. The following preparation steps are needed for conducting the treadmill test, first of all preparation was the instruction $(12,13,14,15)$

Avoid all caffeine containing products 24 hours before the test.

Do not do any exercise or hard physical activity at least 12 hours before testing, and get a good night's sleep.

*Specialist in family medicine, Baghdad teaching hospital.

** Interventional cardiologist, Medical city of Baghdad.

*** Interventional cardiologist, Medical city, Iraqi Center for Heart

Disease.

alnagar_1972,yahoo.com
Do not eat anything after midnight.

Do not smoke or use any tobacco after midnight.

Alcohol should not be consumed within 12 hours of the test.

Bring a list of the current medicine used.

Arrive 20 minutes prior to the test.

Wear loose comfortable clothing and comfortable walking shoes.

Avoid wearing necklaces or clothing with metal on it (metal buttons, sequins, brooches, etc.).

Prohibit drink anything within four hours of the test; medicine can be taken with a sip of water.

Second preparation was clinical preparation, A detailed explanation of the testing procedure should be given by a specialist physician to the patient outlining risks and possible complications. A brief history and physical examination should be done to rule out contraindications of test or to detect important clinical signs. A standard resting 12-lead ECG should be obtained 16,17().

A third preparation was the skin Preparation. The interface between the skin and the electrode must be optimal, The areas where electrodes will be applied should be shaved with a battery-operated trimming device, to decrease the incidence 
of abrasions, or with a standard razor. No bath or shower with soaps or other moisturizers prior to the test. No powder or talc should be applied to the skin Alcohol-saturated gauze should be used to clean and remove oil from the skin $(18,19)$.

Aim of the Study: The present study aims to assess the methods of treadmill preparation and demonstrate the frequency of inconclusive result with causes of premature termination of the exercise tolerance test (ETT).

\section{Patients and methods:}

The study sample consisted of persons of all ages and both sexes attending Mosul cardiac center during the study period. Such patients were assessed by specialist in the cardiac unit by taking clinical history and examination to reveal drug history and presence of associated diseases. Consequently, fitness for the test was decided. Appointment was determined for patients who were not contraindicated for the ETT. At the same time, instructions about preparation for ETT were delivered to patients in a special printed form. Patients were also informed about safety of the test. On the day of ETT, patients were re-examined by the in-charge physician in ETT room. At this stage, patients are interviewed by the researcher to collect the required data and assess patients' preparation. Results of ETT are recorded and evaluated by the specialist whether conclusive (positive or negative for ischemia) or inconclusive (equivocal or incomplete). In addition, causes that indicated discontinuation of EST was recorded according to the specialist's decision. Preparation for exercise tolerance test (ETT) included preparation of ETT room, preparation of patients and technicians' preparation. In the current study, only the preparation of patients was assessed. Preparation was assessed for each patient by recording the following criteria (table A).

Table(A) : Assessing patients' preparation

\begin{tabular}{|l|}
\hline Patients' preparation \\
\hline 1. Fasting \\
\hline 2. Mid-night cessation of smoking \\
\hline 3. Cessation of drug \\
\hline 4. Avoidance of physical efforts \\
\hline 5. Avoidance of soap bathing \\
\hline 6. Avoidance of powder usage \\
\hline 7. Safety awareness \\
\hline Total scores \\
\hline Percent from total \\
\hline
\end{tabular}

Each criteria was scored as (1) if present and (0) if absent. Then, total score of each patient was summed and recorded as a percent $(\%)$. The final score was assessed according to the table(B).
Table(B): Preparation score of studied sample

\begin{tabular}{cc}
\hline Preparation state & Preparation score \\
\hline Excellent & $90 \%$ and more \\
\hline Good & $\mathbf{7 0 \% - 8 9 \%}$ \\
\hline Moderate & $45 \%-69 \%$ \\
\hline Bad & $\mathbf{1 0 \% - 4 4 \%}$ \\
\hline Not prepared & $<10 \%$ \\
\hline
\end{tabular}

Statistical Analysis: The obtained data were processed by applying SPSS impacted program version 17. P-value was considered statistically significant if its value was $\leq 0.05$.

Results:

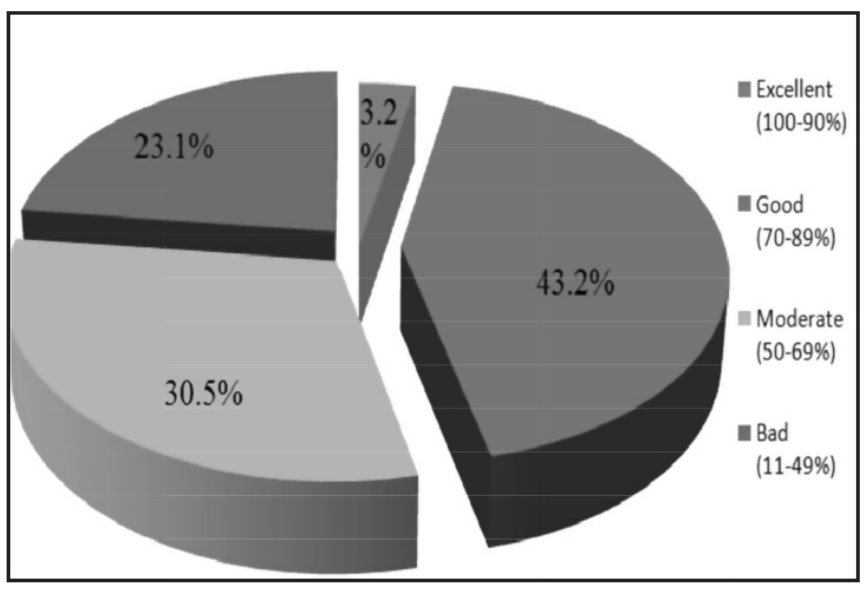

Figure (1): Score of patients' preparation foe ETT

Table (1): Preparation status according to sex

\begin{tabular}{cccccccc}
\hline \multirow{2}{*}{ Gender } & \multicolumn{2}{c}{ Not prepared } & \multicolumn{2}{c}{ Prepared } & \multicolumn{2}{c}{ Total } & \multirow{2}{*}{ p-value } \\
\cline { 2 - 7 } & No. & $\%$ & No. & $(\%)$ & No. & $\%$ & \\
\hline Male & 54 & 39.4 & 286 & 62.7 & 340 & 57.3 & \\
\hline Female & 83 & 60.6 & 170 & 37.3 & 253 & 42.7 & 0.000 \\
\hline Total & 137 & 23.1 & 456 & 76.9 & 593 & 100 & \\
\hline
\end{tabular}

Table (2): Preparation status according to educational level

\begin{tabular}{|c|c|c|c|c|c|c|c|}
\hline \multirow{2}{*}{ Education } & \multicolumn{2}{|c|}{ Not prepared } & \multicolumn{2}{|c|}{ Prepared } & \multicolumn{2}{|c|}{ Total } & \multirow{2}{*}{ value-p } \\
\hline & No. & $\%$ & No. & $\%$ & No. & $\%$ & \\
\hline Illiterate & 35 & 25.5 & 82 & 18.0 & 117 & 19.7 & \\
\hline Primary & 49 & 35.8 & 148 & 32.4 & 197 & 33.2 & \\
\hline Secondary & 16 & 11.7 & 97 & 21.3 & 113 & 19.1 & 0.036 \\
\hline High & 37 & 27.0 & 129 & 28.3 & 166 & 28.0 & \\
\hline Total & 137 & 23.1 & 456 & 76.9 & 593 & 100 & \\
\hline
\end{tabular}


Table (3): Methods of preparation status according to results of ETT

\begin{tabular}{|c|c|c|c|c|c|c|c|}
\hline \multirow{2}{*}{ Methods of preparation } & \multicolumn{2}{|c|}{ Conclusive Result } & \multicolumn{2}{|c|}{ Inconclusive Result } & \multicolumn{2}{|c|}{ Total sample } & \multirow{2}{*}{ p-value } \\
\hline & No. & $\%$ & No. & $\%$ & No. & $\%$ & \\
\hline Fasting & 94 & 77.7 & 27 & 22.3 & 121 & 20.4 & 0.000 \\
\hline Cessation of drug* $(n=362)$ & $\begin{array}{c}77 \\
(65.3)\end{array}$ & --- & $\begin{array}{c}41 \\
(34.7)\end{array}$ & --- & $\begin{array}{c}118 \\
(32.6)\end{array}$ & -- & 0.04 \\
\hline Avoidance of physical efforts & 264 & 63.6 & 151 & 36.4 & 415 & 70.0 & 0.03 \\
\hline Total & 361 & 60.8 & 232 & 39.1 & 593 & 100.0 & 0.000 \\
\hline
\end{tabular}

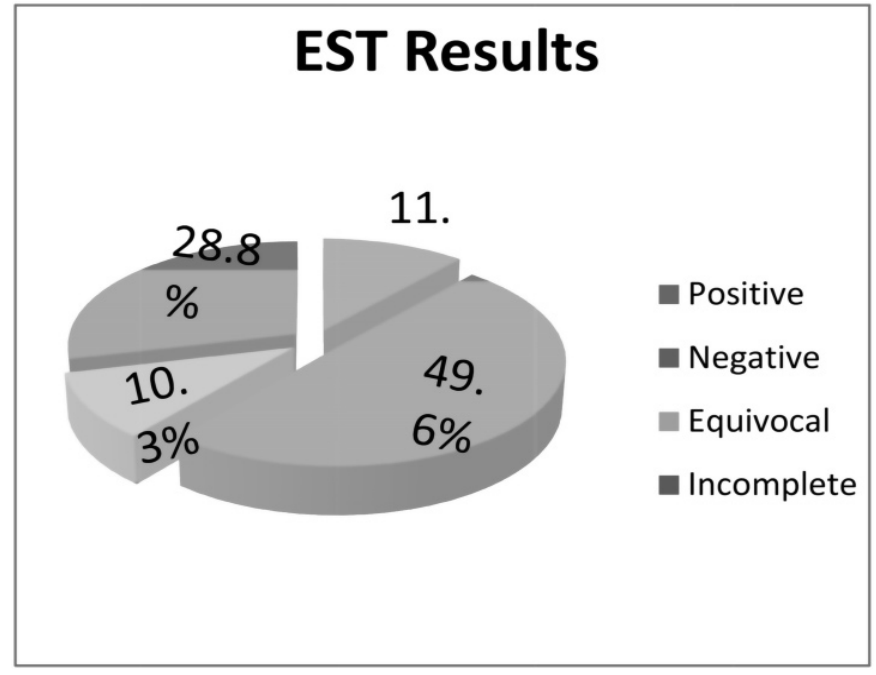

Figure (2): Results of ETT of study sample

percentage of unprepared patients was significantly higher among females than males' patients $(\mathrm{p}=0.000)$. Proportion of prepared patients among illiterate was $18.0 \%$ and significantly raised to $21.3 \%$ among patients with secondary level of education $(\mathrm{p}=0.004)$. Inconclusive result has been reported to occur in about $39.1 \%$ of studied sample. It was an independent modifiable predictor of poor cardiac outcome which limit the utility of the ETT. Further testing after an inconclusive ETT should be used to improve the diagnostic accuracy for detecting CHD and enhancing risk assessment.

Table(4): Preparation status according to results of ETT

\begin{tabular}{cccccccc}
\hline \multirow{2}{*}{ Results of ETT } & \multicolumn{2}{c}{$\begin{array}{c}\text { Not } \\
\text { prepared }\end{array}$} & \multicolumn{2}{c}{ Prepared } & \multicolumn{2}{c}{ Total } & p-value \\
\cline { 2 - 6 } & No. & $\%$ & No. & $\%$ & No. & $\%$ & \\
\hline $\begin{array}{c}\text { Total conclusive } \\
\text { Results }\end{array}$ & 56 & 40.9 & 305 & 66.8 & 361 & 60.9 & \\
\hline $\begin{array}{c}\text { Total } \\
\text { Inconclusive } \\
\text { Results }\end{array}$ & 81 & 59.1 & 151 & 33.2 & 232 & 39.1 & 0.001 \\
\hline Total & 137 & 23.1 & $£ 04$ & $\vee 4,9$ & 094 & $1 \cdots$. & \\
\hline
\end{tabular}

Table (5): Causes of premature termination of ETT

\begin{tabular}{ccc}
\hline \multirow{2}{*}{$\begin{array}{c}\text { Causes of premature termination } \\
\text { of ETT }\end{array}$} & \multicolumn{2}{c}{ Incomplete ETT } \\
\cline { 2 - 3 } & Frequency & Percent \\
\hline Subjective (stopped on request) & 71 & 41.5 \\
\hline Ataxia & 37 & 21.6 \\
\hline SVT & 29 & 16.9 \\
\hline Angina & 16 & 9.4 \\
\hline Dyspnea & 6 & 3.5 \\
\hline Hypotension & 3 & 1.8 \\
\hline Others & 9 & 5.3 \\
\hline Total & 171 & 100.0 \\
\hline
\end{tabular}

\section{Discussion:}

The present study shows that males below fifty years old were referred to ETT more frequently than females of the same age group. While at older age, female patients were examined more frequently $(p<0.05)$. This might be due to the fact that the incidence of ischemic heart disease usually increasing by advancing age $(20,21,22,23)$. About three quarters of the referred cases were at age 40-60 years this might be due to excessive awareness for the chest pain or might be a silent myocardial infarction that occur in older age patients were already diagnosed from other clinical presentation. Wellpreparation for ETT was recorded in male more than females and educated patients more than illiterates regardless their residence. Twenty percent of sample (20.4\%) was fasting before testing and they constituted only $11.6 \%$ of incomplete results $(p=0.000)$. A study achieved by Channer $(24)$ in 2008 compared different dietary constituents and their effect on the chest pain threshold in 14 patients between $41-73$ years of age. He found that impaired effort tolerance and a lower chest pain threshold recorded more after high calorie containing liquid meals. Meals rich in carbohydrate have greater effects than meals where the majority of calories are derived from fat. He concluded that patients should be advised to avoid ETT at least in the first 30 minutes after eating. Moreover, MacDonald(25) et al in 
1997 found that onset of chest pain during ETT occurs earlier after a high carbohydrate meal than in the fasted state despite similar hemodynamic adjustments. While a high fat meal does not affect exercise time. A meta-analytic approach to examine the effects of caffeine ingestion on ratings of performance of ETT reviewed twenty-one studies found that caffeine reduced ETT performance by $5.6 \%$ (95\% CI was $-4.5 \%$ to $-6.7 \%)(26,27)$. Although the current study cannot prove the association of smoking with accomplishing ETT, a study by Yamaji in japan 2012 concluded that exercise performance was improved by the 7 days of smoking abstinence. They stated that smoking status should be considered in the evaluation of physical fitness data $(28,29)$. The present study confirmed a significant association between change in physical activity habits and cardiorespiratory suitability for ETT $(\mathrm{p}=0.03)$. such result agrees with research studying effects of physical activity on exercise tests and respiratory function by Addy et al in 2003. The later authors found that being habitually active and without recent strenuous physical activities were associated with better cardiorespiratory fitness for ETT in both men and women $(30,31,32)$.

\section{Conclusion:}

It was concluded that patients must be well prepared for ETT. They should not only know the purpose of the test, but also signs and symptoms that indicate the test should be stopped. Physicians, nurses, and ECG technicians can ensure patient safety by encouraging them to immediately communicate discomfort at any time during the treadmill test.

\section{Author contributions:}

Dr. Zahraa H.Ismaeel: Study conception, Study design .

Dr. Zaid Abedel-Elah Mustafa Al_Najjar : Acquisition of data analysis, Interpretation of data.

Dr.Salah Mahdy Majeed : Drafting of manuscript , Critical revision

\section{References:}

1- Moskowitz D, Kozzumi L, 2000. Test-Retest Reproducibility of Heart Rate Recovery after Treadmill Exercise. Health Care Almanac \& Yearbook. New York, NY: Faulkner \& Gray. 2000 2- American Academy of Family Physicians, 1998. Facts about Family Practice. American Academy of Family Physicians; 1998.

3- Lloyd-Jones DM, Larson MG, Beiser A, Levy D.1999. Lifetime risk of developing coronary heart disease. Lancet. 1999,Jan 9353(9147):89-92.

4- Phibbs B, Fleming T, Ewy GA, 1988 Frequency of normal coronary arteriograms in three academic medical centres and one community hospital. Am J Cardiol.1988, Sep 162(7):472474
5- Kugelmass AD, Houser F, Simon A., 2001. Diagnostic results: Gender continues to make a difference. J Am Coll Cardiol.2001, 37:497.

6- Cheitlin MD, Armstrong WF, Aurigemma GP, 2003. ACC/ AHA/ASE Guideline Update for the Clinical Application of Echocardiography: Summary Article: A Report of the American College of Cardiology/American Heart Association Task Force on Practice Guidelines (ACC/AHA/ASE Committee to Update the 1997 Guidelines for the Clinical Application of Echocardiography). Circulation.1997, September 2, 108(9):1146-1162.

7- Feil H, Seigel ML., 1928.Electrocardiographic changes during attacks of angina pectoris. Am J Med Sci.1928, 175:255.

8- Master AM, Oppenheimer ET. 1929. A simple exercise tolerance test for circulatory efficiency with standard tables for normal individuals. Am J Med Sci.1929, 177:223.

9- Braunwald E, Antman EM, Beasley JW, 2002. ACC/AHA 2002 guideline update for the management of patients with unstable angina and non-ST-segment elevation myocardial infarction--summary article: a report of the American College of Cardiology/American Heart Association task force on practice guidelines (Committee on the Management of Patients With Unstable Angina). J Am Coll Cardiol.2002, Oct 2 40(7):1366-74.

10-Michaelides AP, Psomadaki ZD, Dilaveris PE, Improved detection of coronary artery disease by exercise electrocardiography with the use of right precordial leads. $N$ Engl J Med. 1999. Feb 4 340(5):340-5.

11-American Heart Association.2008. Heart attack and angina statistics. Available at http://www.americanheart.org/ presenter.jhtml? identifier $=4591$.

12- Fletcher GF., Schlant RC., The Exercise Test, Hurst's The Heart,8th Editin,Pp.423-40.

13-Fitzgerald P, Goodacre SW, Cross E,; 2011. Costeffectiveness of point-of-care biomarker assessment for suspected myocardial Acad Emerg Med.2011, May;18(5):48895. [abstract]

14- Megnien JL, Simon A; 2009. Exercise tolerance test for predicting coronary heart disease in asymptomatic Atherosclerosis. 2009 Aug;205(2):579-83. [abstract]

15-Hill J, Timmis A; 2002. Exercise tolerance testing. BMJ. 2002,May 4;324(7345):1084-7.

16-Siegler JC, Rehman S, Bhumireddy GP; 2011. The accuracy of the electrocardiogram during exercise stress test based on heart PLoS One. 2011, 6(8):e23044. [abstract] 17-Miller TD; 2011. Stress testing: the case for the standard treadmill test. Curr Opin Cardiol.2011, Sep;26(5):363-9.

18-Jain M, Nkonde C, Lin BA; 2011. 85\% of maximal agepredicted heart rate is not a valid endpoint for exercise $J$ Nucl 
Cardiol. 2011, Dec; 18(6):1026-35.

19-Ileana L. Pina LI., Balady JG, Hanson P., Arthur J. Labovitz JA., et al; 1995. Guidelines for Clinical Exercise Testing Laboratories: A Statement for Healthcare Professionals from the Committee on Exercise and Cardiac Rehabilitation, American Heart Association. Circulation. 1995, 91:912-21.

20- O'Malley PG, Redberg RF. ; 2010. Risk refinement, reclassification, and treatment thresholds in primary prevention of cardiovascular disease: incremental progress but significant gaps remain. Arch Intern Med.; 2010, 170(17):1602-3.

21- Fowler-Brown A, Pignone M, Pletcher M.; 2004. Exercise tolerance testing to screen for coronary heart disease: a systematic review for the technical support for the U.S. Preventive Services Task Force. Ann Intern Med. 2004; 140(4): W9-24.

22- Lloyd-Jones DM, Adams RJ, Brown TM. ;. Heart disease and stroke statistics - 2010 update: a report from the American Heart Association. Circulation. 2010;121(7):e46-215.

23- Vasan RS, Sullivan LM, Wilson PW. ; 2005. Relative importance of border line and elevated levels of coronary heart disease risk factors. Ann Intern Med.2005;142(6):393-402

24- Lam YF, Wilson TA, Channer SK. ; 1996. The effect of meals of differing composition on exercise tolerance in patients with angina pectoris. Eur Heart 1996, J 17 (3): 394-398.

25- KearneyKT, Charlesworth A, Cowley JA, Macdonald AI. ; William Heberden Revisited: Postprandial AnginaInterval between Food and Exercise and Meal Composition Are Important Determinants of Time to Onset of Ischemia and Maximal Exercise ToleranceFREE. J Am Coll Cardiol. 1997;29(2):302-307

26- Doherty M, Smith PM. ; 2005. Effects of caffeine ingestion on rating of perceived exertion during and after exercise: a meta-analysis. J Am Coll Cardiol.2005, 15(2):69-78.

27- Astorino TA, Roberson DW.; 2010. Efficacy of acute caffeine ingestion for short-term high-intensity exercise performance: a systematic review. J Am Coll Cardiol.2010, 24(1):257-65

28- Hashizume K, Yamaji K, Kusaka Y, Kawahara K.; 2000. Effects of abstinence from cigarette smoking on the cardiorespiratory capacity. Med Sci Sports Exerc.2000, Feb;32(2):386-91.

29- $\quad$ Asthana A, Piper ME, McBride PE, Ward A, Fiore $M C$, Baker TB, ; Long-term effects of smoking and smoking cessation on exercise stress testing: three-year outcomes from a randomized clinical trial. Am Heart J. 2012. Jan;163(1):8187.

30- LiJ, SiegristJ.Physical activity and risk of cardiovascular disease--a meta-analysis of prospective cohort studies. Int $J$ Environ Res Public Health. Feb;9(2):391-407.

31-Cheng YJ, Macera CA, Addy CL, Sy FS, Wieland
D, Blair SN.; 2003. Effects of physical activity on exercise tests and respiratory function. Br J Sports Med. 2003, Dec;37(6):521-8.

32- American Heart Association; 2010. Selecting a Noninvasive Imaging Study after an Inconclusive Exercise Test. Circulation.2010;122:1514-1518. 